\title{
The immature stages of two Caladomyia Säwedall, 1981 species, from São Paulo State, Brazil (Chironomidae, Chironominae, Tanytarsini)
}

Susana Trivinho-Strixino ${ }^{1}$

Giovanni Strixino ${ }^{1}$

\begin{abstract}
The pupae and larvae of Caladomyia ortoni Säwedall, 1981 and Caladomyia riotarumensis Reiff, 2000, from São Paulo State, are described and illustrated. Caladomyia ortoni Säwedall, $1981=$ Nimbocera paulensis Trivinho-Strixino \& Strixino, 1991, syn. nov.
\end{abstract}

Keywords. Caladomyia; Chironomidae; Diptera; immature stages; São Paulo, Brazil.

\section{INTRODUCTION}

The genus Caladomyia was described by SäwedALL (1981) with material collected in Amazonas by E. J. Fittkau and F. Reiss in the decades of ' 60 and ' 70 . In his work this author describes eight new species. In the revision of the genus by ReIFF (2000) new species were described and recognized 18 species for the genus, of which one in Central America, 16 in the Amazonian region and one in São Paulo State. Although the species of this genus are apparently common in the chironomid fauna of South America, little is known about their immatures. Besides the description of the pupal exuviae of C. spixi by SäwEDALL (1981), the only species whose larvae and pupa stages are known is Caladomyia friederi Trivinho-Strixino \& Strixino, 2000. It lives associated to aquatic macrophytes of the littoral areas of ponds and reservoirs at São Paulo State. The studies that have been carried on by the group of the Laboratorio de Entomologia Aquática da Universidade Federal de São Carlos tries to incorporate information about the Chironomidae species of São Paulo State, and to maintain larval rearing in laboratory conditions to establish the complete identity of the adults and immature of this family.

The immature stages of the two species here described $(C$. ortoni e $C$. riotarumensis) were reared in laboratory and specialists of the München Museum confirmed the adult identification. The larvae of $C$. ortoni were originally identified as belonging to the genus Nimbocera and described as $N$. paulensis Trivinho-Strixino \& Strixino, 1991. Only recently, after the complete establishment of the relation between immature and adult, a correct taxonomic identification was possible.

The morphological terminology follows $\mathrm{S}_{\text {ÆTHER }}$ (1980). The term "taeniae" was used for any broad flattened seta on the pupa (LANGTON 1994).

Caladomyia ortoni Säwedall (Figs 1 - 6)

Caladomyia ortoni Säwedall, 1981: 132 (adult male).

Nimbocera paulensis Trivinho-Strixino \& Strixino, 1991: 175 ( $^{\text {th }}$ instar larvae). Syn. nov.

Material examined: 2 larvae, São Paulo, São Carlos, Universidade Federal de São Carlos (UFSCar) campus, Fazzari reservoir, 5.IV.1992, leg. S. Trivinho-Strixino; 1 larva with pupa, São Paulo, São Carlos, Represa da Mata, Fazenda Canchim, 10.IX.1996, leg. S. Trivinho-Strixino; 1 pupal exuvia + pharate male on same slide, São Paulo, São Carlos, Represa da Colônia, Fazenda Canchim, 11.IX.2000, leg. S. TrivinhoStrixino; 2 male pupal exuviae; 1 female pupal exuvia, São Paulo, São Carlos, Represa da Mata, Fazenda Canchim, 30.X.2000, leg. S. TrivinhoStrixino; 1 male pupal exuvia + adult male on the same slide, Lagoa Cabiúnas, Rio de Janeiro, Macaé, 15.XII.1999, leg. A. Sanseverino.

Pupa (exuviae) $(\mathrm{n}=5)$. Abdominal length $3.0 \mathrm{~mm}$.

Pupal exuvia pale yellowish. Cephalothorax: frontal setae elongate, slender, near $60 \mu \mathrm{m}$ long, mounted apically on welldeveloped conical cephalic tubercles (Fig. 1). Thoracic horn slender and smooth, about $370 \mu \mathrm{m}$ long. Thorax smooth with 
weak granulation close to median suture; scutal tubercle absent (Fig. 2). Wing sheath with short nose; pearl row absent. Thoracic setation: on both sides 3 precorneals $\left(\mathrm{PC}_{1-3}\right)$ situated in front of the thoracic horn basal ring; $\mathrm{PC}_{1}$ longer than $\mathrm{PC}_{2-3}$. Two lateral antepronotals $\left(\mathrm{Laps}_{2-3}\right)$ close together and ventral. Four dorsocentrals $\left(\mathrm{DC}_{1-4}\right)$ present and situated in two widely separated pairs.

Abdomen (Fig. 3). Tergite I and VII without shagreen; II with homogenous central field of fine shagreen sparse medially; III with a pair of anterior fields of fine shagreen and a pair of posteromedian curved long bands of spines; IV with a pair of median s-shaped long bands of spines; $\mathrm{V}$ with a median pair of s-shaped longitudinal band of short bifid or trifid spinules; VI with an anterior pair of oval patches of bifid and trifid spinules; VIII with fine shagreenation around the anterior pair of dorsal taeniate setae. Hook row occuping 1/2 width of segment. Pedes spurii A absent; B present on segment II. Segment VIII with broad posterolateral anal comb consisting of 12-13 marginal teeth and several overlapping ventral teeth (Fig. 4). Anal lobe well developed with complete fringe of about 27-35 taeniae in a single row and 2 pair of dorsal taeniae. Abdominal setation as Table I.

$4^{\text {th }}$ instar larva (complementary description).

The larva (originally described as Nimbocera paulensis) presents as main characteristic the antennae mounted on proeminent pedestal with short distal spur and large Lauterborn organs arising from tip of segment 2 on long pedicels, spirally for about $2 / 3$ of their length. Claws of posterior parapods simple (Trivinho-StRixino \& STRIXINO 1991).

Dorsal surface of head. Clypeal (S3) simple with base plumose (Fig. 6). Labrum. SI comb-like, bases fused. SII distally plumose, situated on short pedestal; SIII simple, seta-like; SIV present(Fig. 5). Labral lamella well developed. Pecten epipharyngis consisting of 3 distally serrated scales. Premandible with 3 teeth; brush well developed.

Differential diagnosis. The presence and the pattern of spine distribution on tergites III and IV observed in C. ortoni

Table I. Pupal abdominal setation of Caladomyia ortoni (the numbers refers to pairs of setae).

\begin{tabular}{lcccc}
\hline & 0-setae & dorsal & ventral & lateral \\
\hline I & & 2 & 1 & \\
II & 1 & 3 & 3 & 3 \\
III & 1 & 5 & 4 & 3 \\
IV & 1 & 5 & 4 & 3 \\
V & 1 & 5 & 4 & $3 T^{*}$ \\
VI & 1 & 5 & 4 & $3 \mathrm{~T}$ \\
VII & 1 & 5 & 4 & $4 \mathrm{~T}$ \\
VIII & 1 & $1+1 \mathrm{~T}$ & & $5 \mathrm{~T}$ \\
\hline
\end{tabular}

$* \mathrm{~T}=$ taeniae pupae differ completely of the other two described species, $C$. spixi Säwedall, 1981 and $C$. friedri, and of the $C$. riotarumensis Reiff, 2000 here described. On the other hand the bifid and trifid spinules present on tergites $\mathrm{V}$ and VI are similar of those observed on C. spixi pupae; in C. friederi these spinules are not concentrated on fields, but dispersed on tergites II-VI, VIII and IX. Other expressive difference is the presence of developed conical cephalic tubercles, also present in C. spixi, but absent in C. friedri and C. riotarumensis. The partially annulated pedicels of Lauterborn organs and the absence of serrate claws on posterior parapods differentiate the $C$. ortoni larvae from those of $C$. friederi and $C$. riotarumensis larvae.

\section{Caladomyia riotarumensis Reiff}

(Figs $7-18$ )

Caladomyia riotarumensis Reiff, 2000: 190 (adult male)

Material examined. 3 male pupal exuviae, 1 female pupal exuvia, 1 pupal exuvia with pharate male on the same slide and 3 larvae, São Paulo, São Carlos, Universidade Federal de São Carlos (UFSCar) campus, Lagoa Mayaca, 5.V.1998, leg. S. Trivinho-Strixino.

Pupa (exuvia) ( $\mathrm{n}=5$ ). Abdominal length $3.67 \mathrm{~mm}$.

Pupal exuvia pale yellowish. Frontal apotome rugulose. Frontal setae elongate, slender, near $75 \mu \mathrm{m}$ long. Cephalic tubercles absent (Fig. 7). Thoracic horn slender and smooth, about $300 \mu \mathrm{m}$ long (Fig. 8). Thorax smooth with weak granulation close to median suture (Fig. 9). Wing sheath with short nose; pearl row absent. Thoracic setation: on both sides 3 precorneals $\left(\mathrm{PC}_{1-3}\right)$ situated in front of the thoracic horn basal ring; $\mathrm{PC}_{1}$ longer than $\mathrm{PC}_{2-3}$. Two lateral antepronotals $\left(\mathrm{LAps}_{1-2}\right)$. Four dorsocentrals $\left(\mathrm{DC}_{1-4}\right)$ present and situated in two widely separated pairs (Fig. 9).

Abdomen (Fig. 10). Pedes spurii A absent; B present on segment II. Hook row about $1 / 2$ width of segment II. Tergite I without shagreen. II with anterior band of small points. III to V with anterior pair of rounded patches of spines enclosed by bands of fine points; VI with anterior pair of rounded patches

Table II. Pupal abdominal setation of Caladomyia riotarumensis (the numbers refers to pairs of setae).

\begin{tabular}{lcccc}
\hline & 0-setae & dorsal & ventral & lateral \\
\hline I & & 2 & 1 & \\
II & 1 & 4 & 3 & 3 \\
III & 1 & 4 & 4 & $2+1 \mathrm{~T}^{*}$ \\
IV & 1 & 4 & 4 & $3 \mathrm{~T}$ \\
V & 1 & 4 & 4 & $3 \mathrm{~T}$ \\
VI & 1 & 4 & 4 & $3 \mathrm{~T}$ \\
VII & 1 & 3 & 4 & $3 \mathrm{~T}$ \\
VIII & 1 & 1 & $1+1 \mathrm{~T}$ & $5 \mathrm{~T}$ \\
\hline
\end{tabular}

* $\mathrm{T}=$ taeniae 

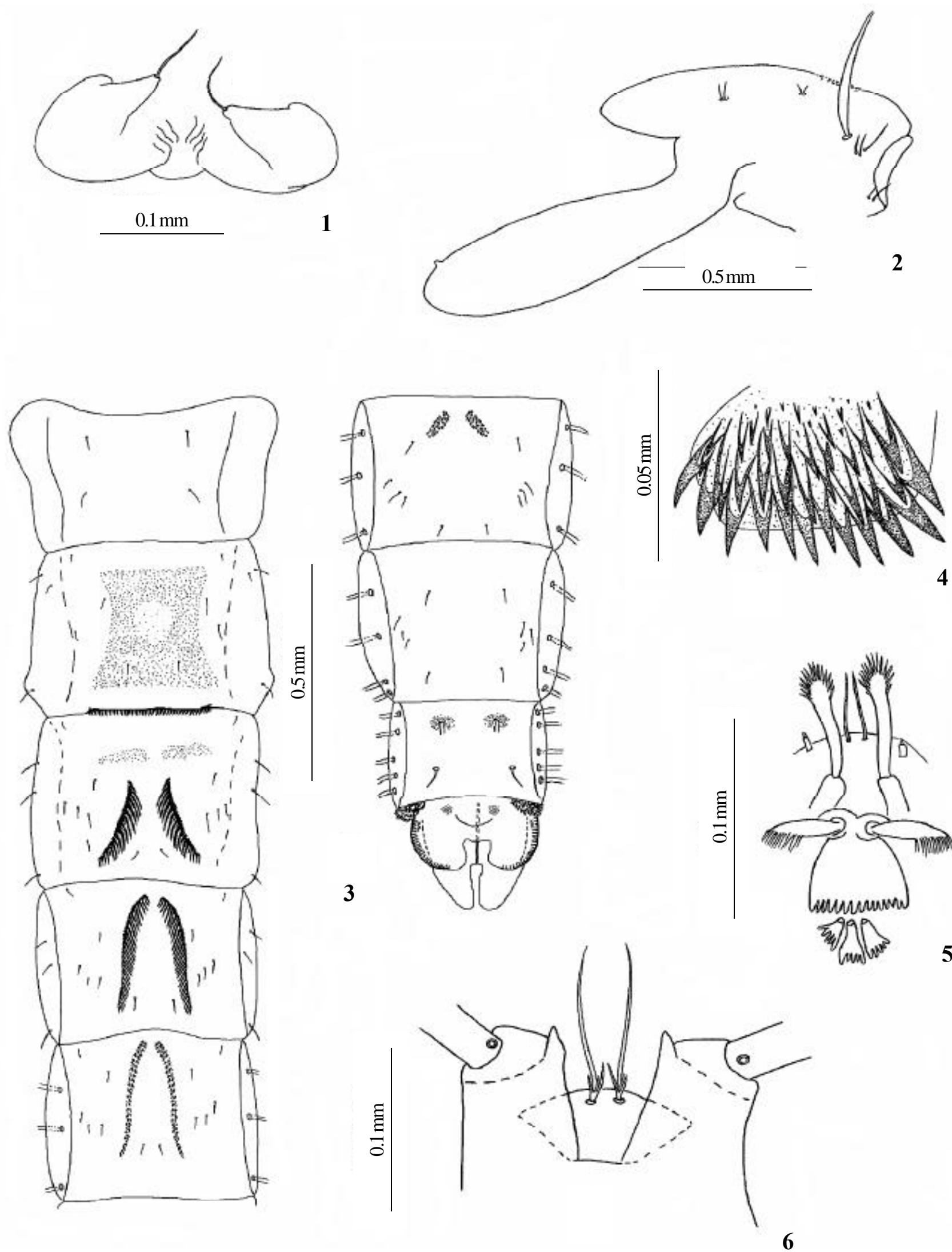

Figs. 1-6. Caladomyia ortoni. Larva and pupa: 1, cephalic tubercle; 2, thorax, lateral; 3, abdomen, dorsal; 4, anal comb; 5, larval labro-epipharyngeal region; 6, larval antennal tubercles and clypeal setae S3. 

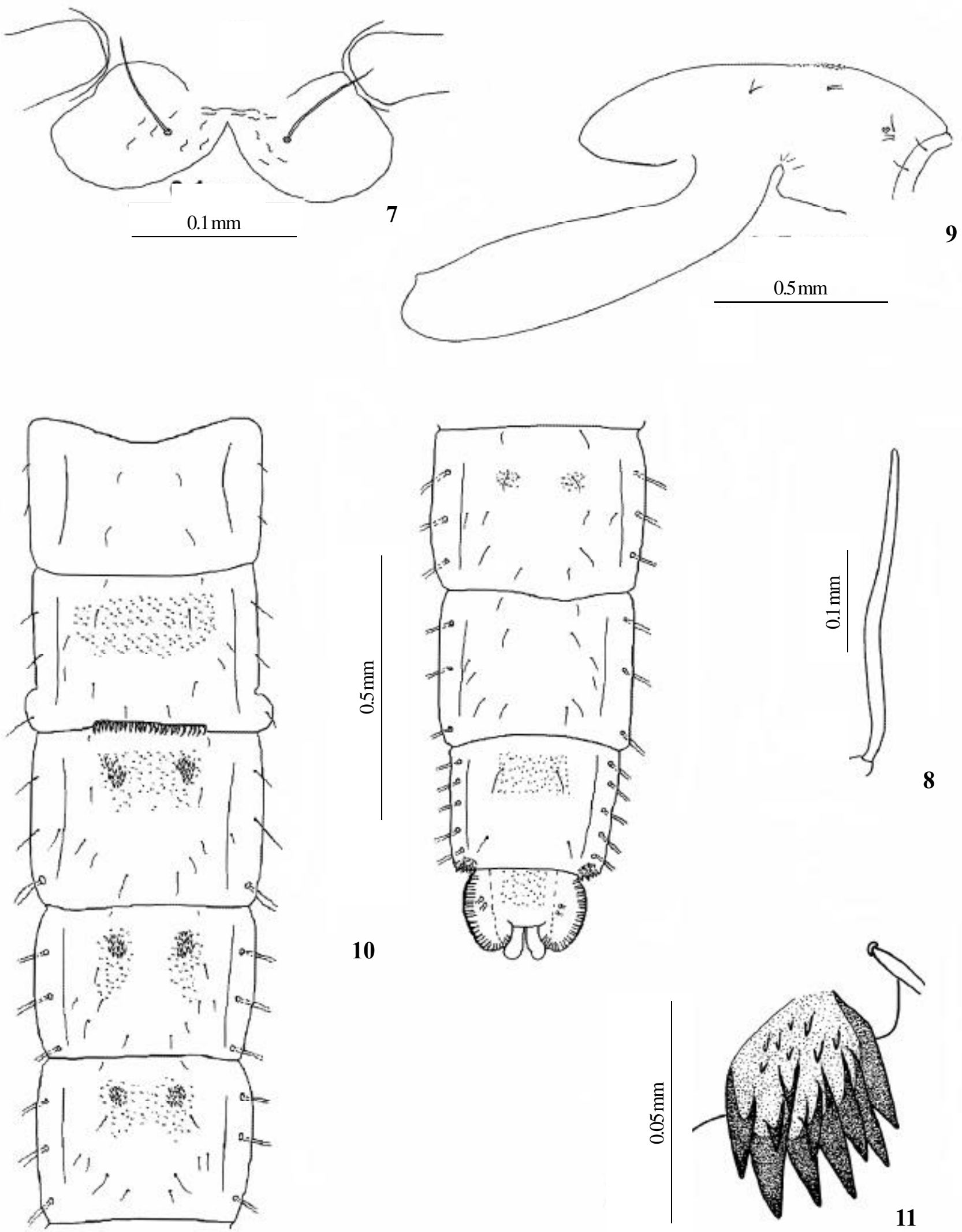

Figs. 7 - 11. Caladomyia riotarumensis. Pupa: 7, frontal apotome; 8, thoracic horn; 9, thorax, lateral; 10, abdomen, dorsal; 11, anal comb. 

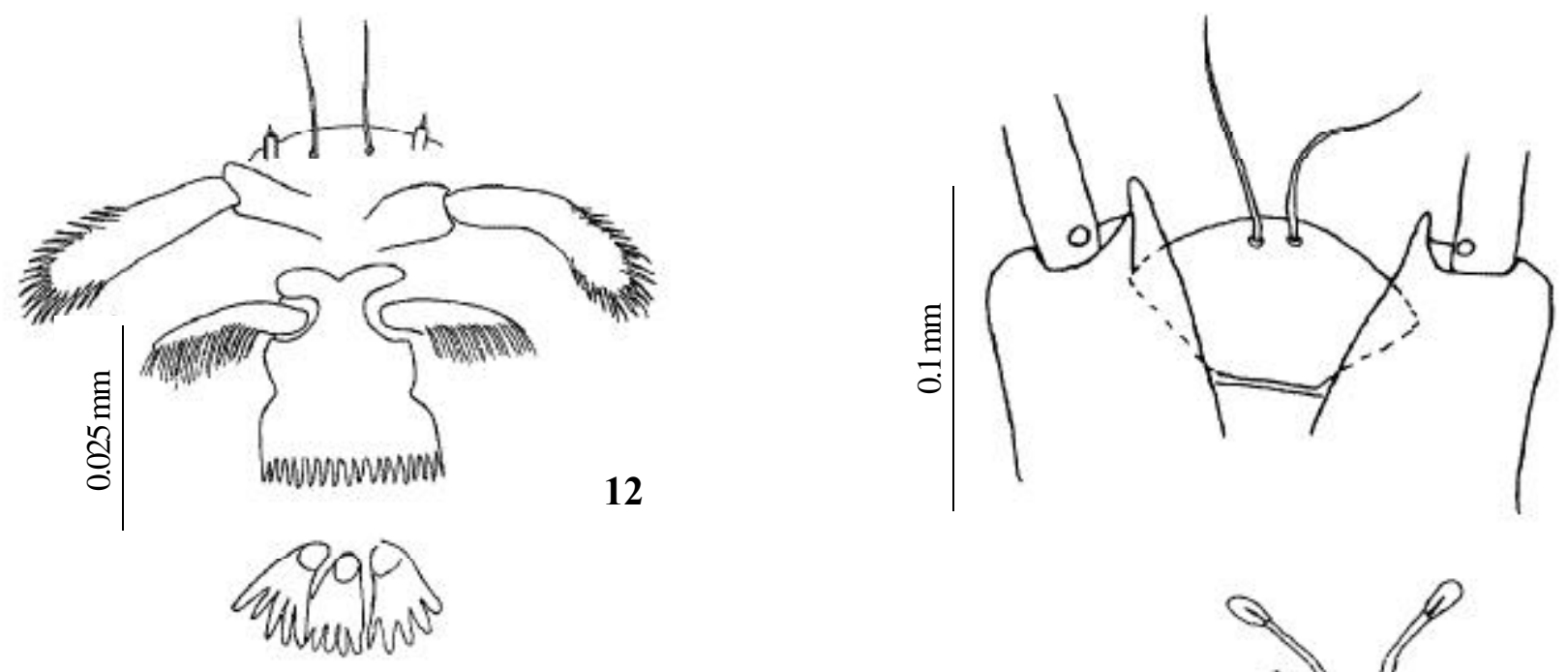

13
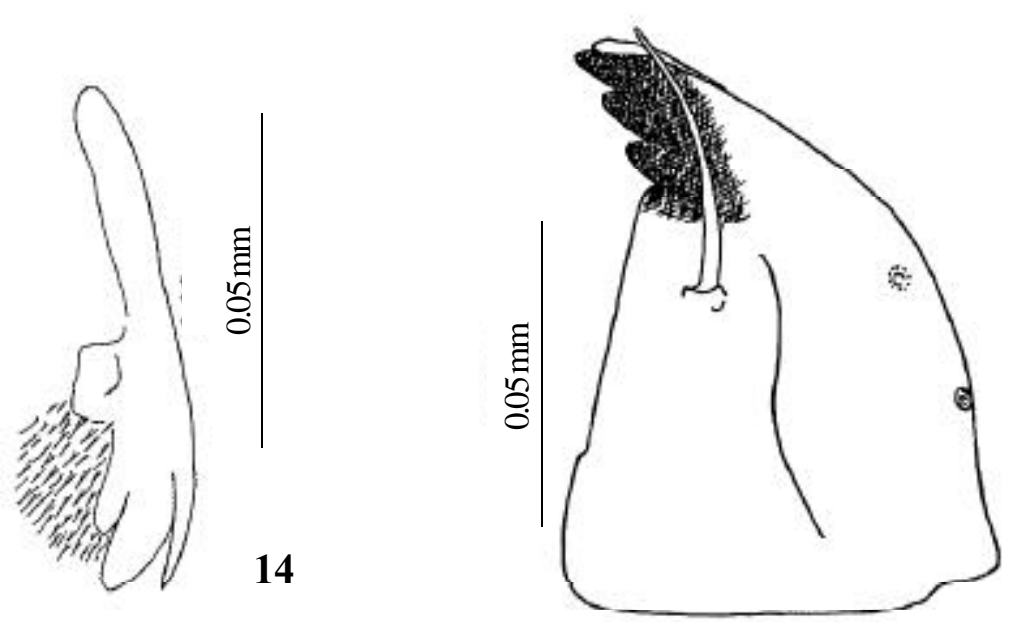

15

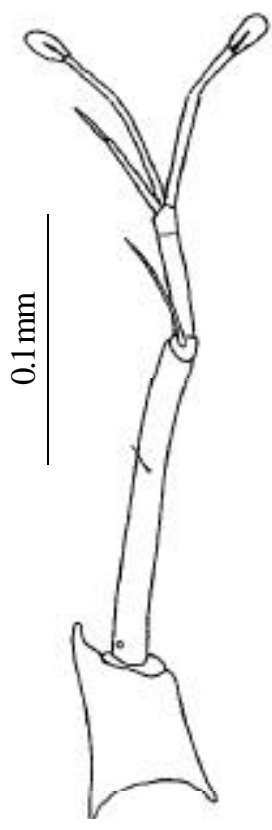

17
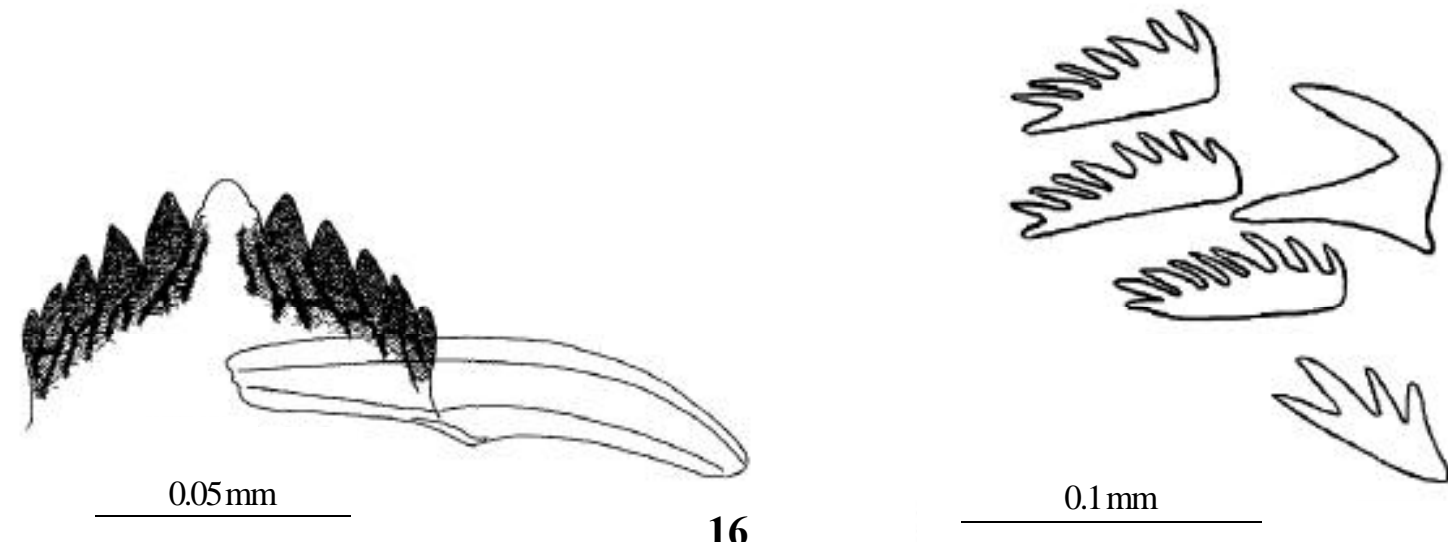

18

Figs. 12 - 18. Caladomyia riotarumensis. Larva: 12, labro-epipharyngeal region; 13, antennal tubercles and clypeal setae S3; 14, premandible; 15, mandible; 16, mentum; 17, antenna; 18, posterior parapod claws. 
of fine spines. VII without shagreen. VIII with anterior bands of fine spines. Segment VIII with posterolateral anal comb of 56 marginal teeth and several additional overlapping ventral teeth (Fig. 11). Anal lobe well developed with complete fringe of ca 30-35 taeniae and 2 pairs of dorsal taeniae. Abdominal setation as Table II.

$4^{\text {th }}$ instar larva $(\mathrm{n}=3)$. Total length about $5.0 \mathrm{~mm}$.

Head: Width $293 \mu \mathrm{m}$, length $375 \mu \mathrm{m}$. Clypeal (S3) simple (Fig. 13). SI comb-like, bases fused; SII distally plumose, situated on pedestal about 1/2 as long as SII; SIII simple, seta-like; SIV present. Pecten epipharyngis with 3 distally serrated scales (Fig. 12). Premandible 80-92 $\mu \mathrm{m}$ long with three teeth (Fig. 14); brush well developed. Antennae 5-segmented on pedestal 60$70 \mu \mathrm{m}$ long bearing a distinct apical tooth (Fig. 17); basal segment $153 \mu \mathrm{m}$ (148-157) longer than flagellum, with basal ring organ and small seta in distal $1 / 2$; segment $2 \frac{1}{2}$ as long as segment 1; Lauterborn organs large, pedicels near $92 \mu \mathrm{m}$ long, longer than segment 3, their proximal half sclerotized. Mandible (Fig. 15) about $110 \mu \mathrm{m}$ with pale dorsal tooth; apical and 2 inner teeth brown. Mentum (Fig. 16) $88 \mu \mathrm{m}$ (84-95) large with pale median tooth slightly notched laterally, 5 pairs of lateral teeth brown. Ventromental plates touching medially.

Abdomen with anal tubules curved down. Posterior parapods, in addition to simple hooks, with some serrate claws (Fig. 18).

Differential diagnosis. C. riotarumensis larva is similar to C. friederi. The main difference is the large dimensions of the first and the proportion of the antennal segments, and the greater length of the Lauterborn organ pedicels. In the pupal exuviae the oval field of spinules on the abdominal tergites agrees with $C$. spixi.

Acknowledgments. This work was partially supported by the Fundação para o Amparo a Pesquisa do Estado de São Paulo (FAPESP) within the BIOTA/FAPESP - The Biodiversity Virtual Institute Program (www.biotasp.org.br). We also thank M. Spies and A. M. Sanseverino, Munich Museum, for the identification of the adults of the species of Caladomyia.

\section{REFERENCES}

Langton, P. H. 1994. If not "filaments", then what? Chironomus 6: 9. ReIfF, N. 2000. Review of the mainly Neotropical genus Caladomyia Säwedall, 1981, with description of seven new species (Insecta, Diptera, Chironomidae). In: M. BAEHR \& M. SPIES (eds). Contributions to chironomid research in memory of Dr. Friedrich Reiss. Spixiana 23: $175-198$.

SÆTHER, O. A. 1980. Glossary of chironomid morphology terminology (Diptera: Chironomidae). Entomologica Scandinavica Supplement 14: 1-51.

Säwedall, L. 1981. Amazonian Tanytarsini II. Description of Caladomyia n. gen. and eight new species (Diptera: Chironomidae). Entomologica Scandinavica Supplement 12: 123-143.

Trivinho-Strixino, S. \& G. STRIXINo. 1991. Duas novas espécies de Nimbocera Reiss (Diptera, Chironomidae) do Estado de São Paulo. Revista Brasileira de Entomologia 35(1): 173-178.

Trivinho-Strixino, S. \& G. Strixino. 2000. A new species of Caladomyia Säwedall, 1981, with description of the female and immature stages (Insecta, Diptera, Chironomidae). In: M. BAEHR \& M. SpIEs (eds). Contributions to chironomid research in memory of Dr. Friedrich Reiss. Spixiana 23: $167-173$. 